\title{
Blockchain for humanitarian action and development aid
}

\author{
Andrej Zwitter ${ }^{*}$ (D) and Mathilde Boisse-Despiaux
}

\begin{abstract}
Blockchain technology is swiftly entering the fields of humanitarian and development aid. While it has the potential to revolutionize the aid sector, e.g., through pairing smart contracts with forecast-based financing, it also has the potential to perpetuate societal problems and add new risks. This essay outlines the use cases of Blockchain technology for the humanitarian and development sectors and reflects on potentials and pitfalls that come with the adaptation of this new technology.
\end{abstract}

Keywords: Humanitarian innovation, Sustainable development goals, Blockchain, Development aid, Governance of innovation

\section{Introduction}

Blockchain technology is rapidly reshaping the digital tools we use to conduct daily transactions. As such, Blockchain has emerged as a disruptive technology, which has not only laid the foundations for cryptocurrencies, but also the field of smart contracts. Critiques raise issues such as data protection and power consumption, and advocates herald a new era of digital transactions. Also, the humanitarian sector has been gripped by this debate.

The features of Blockchain technology-decentralized and trustless ledgers recording transactions across a peer-to-peer network-create, for example, the potential to remove corruption by providing transparency as well as accountability. Developments like this could impact not only the financial sector but also other fields such as supply chain management, digital identity, and smart contracts. In fact, several humanitarian and development organizations are playing with the idea to combine the governmental and private funding instruments with Blockchain technology to increase efficiency, accountability, and transparency. The initiatives, in which the technology is used to distribute and trace aid funding, provide and manage IDs in refugee camps, or create trustworthy land registries, are just a few examples of the utility of Blockchain technology, but they also indicate potential risks, such as to privacy protection.

\footnotetext{
* Correspondence: A.zwitter@rug.nl

University of Groningen, Sophialaan 1,8911 AE Leeuwarden, The Netherlands
}

Opinions on the utility of Blockchain technology are very mixed. Some are enthusiastic; others believe that it is merely hype. For example, Michael Fauscette, CRO of G2 Crowd and author of the G2 Digital Trends Report 2018, highlights the importance of Blockchain for giving people back their identities where governments are absent or unwilling (Sandle 2018). At the same time, he considers potential cyber risks as mostly theoretical, since the technology is considered extremely secure. On the other side of the spectrum, Blockchain is viewed with some doubt given its complex nature and the fact that it requires electricity and internet access, features that many humanitarian crisis areas do not readily and reliably provide (Riani 2018).

To moderate the hype of Blockchain as panacea of all ills in the humanitarian and development sector, we suggest looking at Blockchain technology as a tool like other technologies with its benefits and pitfalls. In the end of the commentary, we will give a list of points that humanitarian and development organizations might want to consider when employing this novel technology.

The ideas presented in this commentary have been galvanized at the Blockchain4SDGs Workshop, Data Research Centre Campus Fryslân, University of Groningen on December 1, 2017 (https://www.rug.nl/cf/events/eventsitems/blockchain4sdgs-workshop n.d.). The workshop was organized as a follow-up event of the Humanitarian Blockchain Summit, Fordham University New York, November 10, 2017, which called for a more nuanced debate on the 
utility of Blockchain technology in the humanitarian sector that would go beyond the hype. The Blockchain4SDGs workshop brought together 25 experts from industry, the humanitarian sector, and academia to discuss the following:

- Blockchain and humanitarian action;

- Blockchain and development;

- Blockchain, international peace and security;

- New approaches in Blockchain technology.

The commentary presents an updated excerpt of the 2018 Workshop report "Blockchain4SDGs" (Zwitter and Herman 2018).

\section{What is Blockchain}

In the last 4 years, a number of high-profile incidents have highlighted the extent to which European consumer supply chains can be complex, opaque, and susceptible to poor practice: the 2013 horse meat scandal, the 2017 contaminated eggs scandal, and the 2013 Bangladeshi factory collapse, to name just a few. Initiatives using Blockchain technology such as Fair Food (Fair Food 2017) - which traces the origins of coconuts sold in the Netherlands back to the farmers who produced them in the Philippines, while at the same time ensuring that people at the beginning of the supply chain receive a fair wage-can lead one to believe that Blockchain technology could lead to supply chains which are simpler, more transparent, and more reliable in the future.

Outside the aid sector Blockchain-enabled supply chains are increasing and function very successfully. "Depending on the product, the supply chain can span over hundreds of stages, multiple geographical (international) locations, a multitude of invoices and payments, have several individuals and entities involved, and extend over months of time. Due to the complexity and lack of transparency of our current supply chains, there is interest in how Blockchains might transform the supply chain and logistics industry" (Marr 2018). Hinging on the design of the specific Blockchain solution for supply chain management, all transactions are potentially public and traceable by every node in the Blockchain. This puts transparency and accountability to a whole new level. With Blockchain technology, contracts and payments in a supply chain can be automated and every single item is traceable at any time. This posits this new technology as a crucial innovation to improve the complex humanitarian supply chain management.

Blockchain technology was initially created in 2008 as the underlying technology of the Bitcoin cryptocurrency (Nakamoto 2008). It solved one particular problem of the digital economy: the double-spending problem or how to ensure that one and the same digital token (e.g., Bitcoin) could not be spent more than once. It has gained momentum among the general public in the past few years, especially after appearing on the cover of The Economist in October 2015 (N/A 2015). The economist stresses the extraordinary potential of Blockchain technology beyond its applications in digital currencies. Blockchain has subsequently been portrayed in many instances as a revolutionary invention, which could change the world as profoundly as the Internet has since the 1990s.

However, understandably, most people still struggle to understand how Blockchain works. Simply put, Blockchain is a decentralized database, which stores a registry of assets and transactions across a peer-to-peer network. The term "asset" can be understood in manifold ways: not only as money but also as ownership, custodianship, contracts, goods, and even personally identifiable information (Warburg 2016). Although peer-to-peer networks already exist to exchange files such as pictures or songs, Blockchain works differently in the sense that it does not duplicate the value which is transferred. Instead, the technology registers that a value has been transferred from one actor to another across a network (Balva 2017). This differentiates Blockchain from cloud solutions and positions it closer to peer-to-peer networks such as BitTorrent.

Moreover, Blockchain functions without any central control system and stores the transaction history in blocks of data that are cryptographically locked together. As it is replicated on every computer that belongs to the network, it is an immutable, secure, and transparent record of all transactions that have ever taken place (Drescher 2017).

On a more technical level, Blockchain is based on a consensus mechanism, which principally relies on two elements: "hashing" and "proof of work" (alternatively "proof of stake" and other proofs). Hashing means creating a fingerprint (a formula made of numbers and letters) of the data elements in the transaction message. It is a way of verifying the authenticity of transactions, thus allowing users to identify whether someone or something intervened with the data (Vermeend 2017).

Before a new transaction is added to the block, transactions need to be verified through "proof of work," a mathematical puzzle which ensures that users do not cheat by knowing upfront who will validate the transaction. Solving this proof of work-puzzle, is also known as "mining," and is performed by members of the network. Hence, all the computers compete to validate the transaction (Vermeend 2017). Once a block has reached its maximum capacity of transaction hashes, it is queued with previous blocks which altogether form the Blockchain (Blockchain.info n.d.).

In essence, Blockchain is a technology that lowers the uncertainty which we face when exchanging value. 
While anonymity is often a core feature of Blockchain technology, trust is not necessarily an issue as all members of the network hold a record of all transactions, making Blockchain almost impossible to tamper with. This is the idea of a "trustless" technology. It also reduces the uncertainty of not having recourse if something goes wrong with transactions. Since Blockchain enables tracing every transaction from the beginning until it is validated and added to a block, users can see whether a mistake has happened, and where in the process it has occurred. Whether the users are anonymous and whether transactions are visible as such in the Blockchain is ultimately a design choice in the specific implementation.

Blockchain evangelists argue that while societies traditionally needed to be called upon governance institutions such as governments and banks to deal with uncertainties around trust, Blockchain could render those institutions obsolete by enabling individuals to exchange value safely and transparently with technology alone, without the need for central third parties (Warburg 2016). Given that many praised aspects of Blockchain technology are not a sine qua non conditions but design choices, this potential might be somewhat overstated. Furthermore, governments and banks also serve other functions, such as safety nets for individual and collective risk management that go beyond mere transactions.

To summarize the technological side of Blockchain technology, which is also referred to as "Distributed Ledger Technology" (DLT), consider the following characteristics:

- Censorship proof, as no single individual can unilaterally decide to dictate the content of the Blockchain;

- Reliable, as one can trust the Blockchain in clarifying and transferring assets correctly;

- Pseudo anonymous, as it identifies owners uniquely using individual pseudonyms, but has the possibility of not retaining or revealing their real-world identity;

- Secure, as it prevents ownership from being manipulated, counterfeited or spent twice;

- Resilient, as it can clarify and transfer ownership even under difficult conditions;

- Consistent, as the chance of getting consistent results increases over time;

- Upstanding, as it maintains its integrity as well as data consistency and ensures security on the level of individual transactions and the whole history of transaction data (Drescher 2017).

At the same time, many of its proclaimed advantages are in fact design choices and are not necessary conditions of the Blockchain-enabled tool. Furthermore, a too naïve reliance on Blockchain technology as a panacea to solve all problems overlooks that it is still merely a technology that also comes with its limitations. Some of its features might not be desirable in all instances. For example, immutability of records also ensures that mistakes and wrong transactions are perpetually on record. In addition, full transparency in the supply chain might not always be desirable, specifically in case of political conflicts. Attribution of funding and association to humanitarian organizations can put them at risk of repercussions. This for example happened to Western NGOs and the UN in the 2003 Iraq war. Aid actors faced repercussions by local insurgents because they were seen as mere tools or even as spies of the US administration-so many organizations had to keep their funding sources and association secret if they wanted unhampered access (Zwitter 2008). In addition, terms used around the technological architecture, such as resilient, take on a different meaning in the aid sector.

Since 2015, some of the world's largest financial institutions have gathered in a consortium, coordinated by a start-up called R3Cev, to research and develop Blockchain database usage in the financial sector (Popper 2015). Moreover, in January 2016, the British government published a report on how the technology could transform the delivery of public services and boost productivity (British Government Office for Science 2016). In May of the same year, the European Parliament approved a proposal for a task force dedicated to monitoring the use of cryptocurrencies and Blockchain technology (Kastelein 2001). Indeed, companies and national and supranational entities are increasingly being forced to pay attention to the use of Blockchain technology as its disruptive potential becomes ever more apparent. Its power is already being felt not only within the financial sector but also in other fields, such as supply chain management, digital identity, and smart contracts, to name just a few.

\section{Blockchain for development and humanitarian aid: implications and applications}

In their article "Blockchain for Good?," Kewell, Adams, and Parry differentiate between the intended use of an artifact (one which is built into its design), and the properties which it assumes, that ultimately allow for a different use of the very same artifact (Kewell et al. 2017). According to Kewell et al., when it comes to the distributed ledger technology, "to focus on a single application or specific use of the Blockchain is to overlook its significance for ethical impacts at the global level" (Kewell et al. 2017). In fact, "Blockchain affordances" relate to the "discernment of what the software can do for sustainable development and environmental protection in parallel with an appreciation of what novel development 
could realize for vulnerable and impoverished communities" (Kewell et al. 2017). Furthermore, the authors argue that there are discussions to be had regarding the practical and ethical considerations in relation to Blockchain in the following fields: Blockchain mining, the emergence of an Internet of values as opposed to the current Internet of information, supply chains, innovation in governance, sharing economy, and financial inclusion.

The utility of Blockchain technology for the development and humanitarian sectors is most likely not to be confined to its original idea of crypto currency (Blockchain 1.0) but shows most promise in the application of the technological advantages, as outlined above, ultimately automatizing many logistical processes, and informational infrastructures, such as the management of digital identity and so called smart contracts (Blockchain 2.0). Developments around Blockchain 1.0 such as criminal activities associated with Bitcoin have attracted much criticism. Blockchain 2.0 seems to increasingly resolve many of the pitfalls and hazards of the former and might be able to epitomize the technological innovation that organizations will increasingly come to rely on in the future.

Two of the most engaging notions introduced are "colored coins" and "qualified money": the idea that moral principles and ethics can be embedded in the code of the distributed ledger technologies and allow individuals to align their spending with their own values. The authors give the examples of the CarbonCoin, which was designed to engage the environmentally conscious community, and that of a Blockchain-based Islamic cryptocurrency, in which transactions are aligned with Muslim values, and which include an anti-radicalization agenda. In the field of humanitarian and development aid, one can easily imagine donations that are digitally earmarked only to be used for certain services or to reach certain communities. It is easy to see why authors argue that Blockchain "may be a boon in developing or politically unstable economies" when paired with radical values (Kewell et al.). It appears, however, that Blockchain technology is less to blame for its political instrumentalization. As it is with every technology, it reproduces current political situations and might thus become yet another tool to reinforce radical over liberal values.

"Qualified money," i.e., task and purpose specific funding might, on the other hand, increases accountability to donors and beneficiaries and reduces corruption. This does come with the potential pitfall that NGOs, which often need to rely on bribes and bargains to gain access to the most vulnerable, might be more restricted in their operational freedom. At the same time, completely transparent chain of transactions, end-to-end from donor to beneficiary, would be a milestone to ensure that no diversion, abuse or misallocation of funds could happen or that "unethical" funds end up in the financial supply chain.

Nir Kshetri underlines the fact that Blockchain technology can be applied not only in banking but also in promoting transparency and reducing fraud and corruption. It could also reduce barriers and costs associated with property registration, promote efficiency in international business-to-business (B2B) trade, and increase access to trade and supply chain finance. At the same time, because the technology is completely digital and can be fully automatized, a wide range of costs can be reduced, resulting in enhanced efficiency within international payment systems, insurance policies, and risk management procedures (Kshetri 2017).

The idea of using Blockchain 2.0 is that through smart contracts many aspects of the supply chain management and contract execution could be automatized with technologies such as Etherium and IOTA. Many humanitarian organizations such as UNICEF and WFP are actively exploring such possibilities regarding cash-based aid and digital identity. An exciting application would be forecast-based financing coupled with smart contracts between funding organizations and implementing partners. One can imagine the use of Big Data to forecast the onset of natural and man-made crises and use objective indicators to trigger smart contract transactions to implementing partners to engage in disaster risk reduction and conflict management preventively. This might not only increase the efficiency of funding instruments but also reduce the degree to which crisis funding is often dependent on political will and bargaining positions of donor countries.

In terms of real-world application within the humanitarian and development sectors, Blockchain is already being used to fight corruption, improve land tenure and property rights, create secure digital identities, and tackle gender inequality. Hundreds of millions of dollars are currently lost to corruption every year, and Blockchain is now being used to trace aid funding in order to stem the flow of corruption (Kenny 2017). The Start Network, a consortium of international aid agencies, which uses Blockchain technology, was created in order to deliver effective aid to the people affected by crises (Poorterman 2017). In fact, Blockchain has implications for supply chains in general: for example, the company, Provenance, uses Blockchain to track materials and products in a transparent and secure way (Project Provenance Ltd 2015).

Distributed ledger technology has also been applied to land tenure and property rights. Traditionally, governments keep records of land properties, but these registries can be lost or manipulated, and owners may not have written proof of ownership. Successful initiatives include the BitLand digital registry created in 
Ghana in 2015, as well as other applications in Georgia, and experiments conducted in both Honduras (Kshetri 2017) and Sweden (Keane 2017). At present, 90\% of the land on the African continent remains unregistered, and in India, landlessness is arguably a more powerful cause of poverty than caste or illiteracy. Consequently, argues Kshetri, Blockchain technology offers a tremendous opportunity for addressing insecurity, corruption, and misuse in the field of land registration (Kshetri 2017).

Digital identity is also a topic in which Blockchain technology is uniquely useful. According to Kewell, Adams and Parry "identity [...] will underpin the digital future and lies at the heart of realising the potential of DLTs (distributed ledger technologies)" (Kewell et al. 2017). Among other initiatives, the government of Estonia has implemented an e-residency scheme through Blockchain, which allows individuals to electronically record their marriage, birth certificates, business contracts, or access services regardless of their residency status (Preiss 2017). Similarly, in 2015, the AID:Tech company used a Blockchain-enabled system to provide refugees, who lived in a camp in Lebanon, with digital identities which were connected to vouchers to buy consumer goods (Gorey 2016).

The technology might also be used to tackle issues affecting women who live in developing countries. The digital identity applications of Blockchain are being used by the UN Office for Project Services (UNOPS), who have launched a pilot project in Moldova to protect children and young women from being illegally trafficked (Sundararajan 2017). In addition, other initiatives using Blockchain allow women to access micro-loans or enable secure money transfers among female entrepreneurs (UN Women 2017). As such, it aims to tackle the issue of women empowerment. To what degree Blockchain really adds value to solving a societal issue rather than a technological one remains to be seen.

As demonstrated, Blockchain technology has potential applications within many domains beyond the financial sector. Furthermore, smart contracts will help improve supply chains for development and humanitarian projects. As we have indicated, some initiatives have already been implemented, and others are still in an early, ideational stage. However, the possibility of creating an immutable ID record may be both a promise as well as a curse, as contracts are automatically executed, this might initially lead to very rigid processes without the human margin of appreciation so often necessary in volatile emergency scenarios. This is but one of many concerns and limitations concerning Blockchain technology, and we now turn to explore these in more detail.

\section{Concerns and limitations}

Although the distributed ledger technology (DLT) has been described as disruptive and revolutionary, it is not a panacea to all of the world's problems and is not without its limitations. There are several concerns that are important to consider. Firstly, Blockchain is a high energy-consuming technology. While attempts to reduce the energy costs already exist, Blockchain will always require servers and computers to process transactions. Therefore, in countries where the Internet is frequently shut down, where there is poor energy infrastructure, and where brownouts are common, DLT rapidly reaches its limits of scalability (Purvis 2017). Internet (or network) access and electricity problems in field environments can be a potential caveat for humanitarian actors successfully implement Blockchain technology. For these cases, workarounds might be possible and given that the ledger updates to a verified status upon accessing the network, Blockchain technology might even provide a desired solution. However, this will most likely depend on the use case scenarios for the technology.

Moreover, Blockchain is often referred to as an open-structure by design. Consequently, privacy and data protection remain a concern, particularly when it comes to identity registries and other Blockchain databases in which personally identifiable information is processed (Baird et al. 2016). In these cases, a decentralized system might not be the desired format and a save cloud environment or virtual user interface environments, which allow remote access to a centralized server system, might be the preferable option. There certainly are potential solutions to using decentralized systems without revealing critical data, such as zero-knowledge proofs. However, the extent to which they can be reasonably implemented within Blockchain technology remains an unanswered question for now.

Beyond privacy concerns, there are also considerations regarding issues around the General Data Protection Regulation of the European Union, regarding questions around data ownership, how to prevent the misuse of data, and how to implement the right to be forgotten (Baird et al. 2016). Since Blockchain provides an immutable, and decentralized ledger, these otherwise desired features may pose a problem if data needs to be permanently purged or changed or if data ownership questions are at stake.

In addressing the concerns above, it becomes evident that the development of Blockchain technology for a sector specific use is in part held back by the absence of a legislative framework. The participants of the Blockchain for Good conference advocated for a federated model: "a guiding hand to set the vision and principles to enable the success of the Blockchain for the greater good." Inspiration for such a framework might come 
from the Linux Foundation, which provides standards for Linux, or the Internet Corporation for Assigned Names and Numbers: a non-profit organization which is responsible for managing the addressing system globally (Baird et al. 2016). A legal framework certainly appears to be necessary for Blockchain to reach its full potential in the fields of development and humanitarianism, or indeed within any other sector. For the humanitarian sector, this means that Blockchain technologies needs to comply with international humanitarian law and human rights law, for example, concerning issues around dual use technology, the principle of distinction and issues around non-discrimination. Furthermore, the humanitarian principles of humanity, impartiality, neutrality, and independence are still among the core principles that should be observed with any technological solutions. Work on big data and the humanitarian principles has shown that there are potential caveats when it comes to the implementation of Big Data solutions (Qadir et al. 2016). Veracity of data and analyses as one of the methodological issues around the use of Big Data in the humanitarian field for example remains just as or even more important when dealing with immutable, distributed ledgers.

In essence, this leads to four criteria that determine the suitability of Blockchain technology for use within the fields of development and humanitarian affairs:

1. Do benefits outweigh the development and scaling costs of the new technology?

2. Is decentralization through distribution, and built-in trust through transparency, a necessary feature of the new technology?

3. Does the digital ledger, as a core of the new technology, need to be immutable?

4. Do the features of the new technology comply with legal norms, humanitarian principles and professional codes of conduct?

If the answer to any of the above questions is a NO, then Blockchain is maybe not the right technological solution for the problems that a humanitarian or development agency might try to solve, or the solution might be unfeasible.

\section{Conclusion}

Blockchain is already being used to fight corruption, improve land tenure and property rights, create secure digital identities, tackle gender inequality, and more. As such, these initiatives contribute to the agenda of the Sustainable Development Goals in innovative ways. There is further huge potential in Blockchain technology, including possible applications within the humanitarian sector. One of the most exciting prospects is the application of smart contracts to automatize funding through forecast-based financing. Paired with Big Data analytics, such models could provide for more efficient and less political funding instruments.

We highlighted ethical considerations and requirements that underpin work within the humanitarian and development sectors. The important question remains whether this new technology complies with established humanitarian principles and professional codes of conduct. The issue of data privacy for example would need to be addressed before the technology could be used within complex, volatile contexts. The stakes are high. Any use of this potentially revolutionary technology must uphold the principle "do no harm."

While certain features of Blockchain technology are often considered to be absolute and intrinsic, we indicated that it is critical to realize that characteristics such as decentralization, transparency, and immutability should be understood as outcomes of intentional choices in developing these technological architectures. These features are by no means necessary or intrinsically good. Such an understanding allows stakeholders to recognize that intentional design choices have to be made around the design of Blockchain-enabled systems in order to ensure the product fully realizes designer's objectives.

The experts of the Blockchain4SDGs workshop further considered it critical that further monitoring and evaluation guidance will be developed for the early stages of exploration and experimentation with new technology trends, in order to improve knowledge sharing and development around the potential of new technology trends, such as Blockchain. The participants concluded that it was critical to build a repository of ongoing initiatives focused on leveraging Blockchain for humanitarian applications and sustainable development. A reference framework such as this should support stakeholders in this sector to make more informed decisions based on best practices and needs for improvement.

When asked which criteria the Blockchain technology should be evaluated upon, workshop participants answered that their organizations and companies should have a specific purpose for using the technology. Indeed, there is currently a hype around Blockchain technology, and it is sometimes used where it is in fact not necessarily needed. Rather than taking the technology in itself as the starting point, a discussion should start with addressing the central humanitarian and developmental challenges and include contextual considerations.

In short, Blockchain technology has great potential. However, it is still in such an early stage of development that its advantages and disadvantages are still not fully understood. Moving forward will require:

- Well-selected implementation choices, 
- Clear ethics guidelines, and

- Common monitoring and evaluation frameworks.

Only then can Blockchain move reasonably and reliably beyond its current hype and can become a standard of implementation for the future of humanitarian action and development aid as well as the Sustainable Development Goals in general.

\begin{abstract}
Acknowledgements
The authors are grateful to the participants of the Workshop "Blockchain for Sustainable Development Goals," Leeuwarden, December 1, 2017, and the contributors to the workshop report, which is available online at: https:// www.rug.nl/cf/news/newitems/blockchain-for-sustainable-development. We would like to thank for their participation in the workshop and their contribution to the report specifically: Adamanti Rachovitsa, Ali Anwaar, Amaranta Luna, Anna-Jorien Prins, David Michels, Dilek Genc, Egon Rijpkema, Evan Yap Peraza, Giulio Coppi, Jonas Bulthuis, Joost Herman, Jorn Poldermans, Kate Dodgson, Koen Hartog, Layne Vandenberg, Leslie Zwerwer, Melissa Amoros, Oskar Gstrein, Richard Adams, Steven Gort, Taynaah Reis, Terry Ling, and Thomas Baar.
\end{abstract}

\section{Availability of data and materials}

All data is referenced and available at the referenced sources.

\section{Authors' contributions}

Both authors have in equal parts contributed to the research and the text. MBD conducted her research under the supervision of AZ. In addition, AZ has conducted the final redaction, language editing, and formatting. Both authors read and approved the final manuscript.

\section{Authors' information}

Prof. Andrej Zwitter is the chair of Governance and Innovation, director of the Data Research Centre and dean of the University College at Campus Fryslân, University of Groningen.

Mathilde Boisse-Despiaux is a Master's student in the Euroculture Programme and did her research internship with prof. Zwitter.

\section{Competing interests}

The authors declare that they have no competing interests.

\section{Publisher's Note}

Springer Nature remains neutral with regard to jurisdictional claims in published maps and institutional affiliations.

Received: 25 July 2018 Accepted: 3 October 2018

Published online: 26 October 2018

\section{References}

Baird C, Chan S, and Hargreaves I (n.d.). White Paper, "Blockchain for Good: Humanising the Blockchain". Blockchain for Good. https://static1.squarespace. com/static/584b0a4b37c5812f78aa6669/t/5851803a5016e172dab2b897/ 1481736252705/The+Blockchain+For+Good+Manifesto.pdf . Accessed 25 July 2018.

Balva C (2017) La Blockchain: Réinventer les rapports de confiance. The Blockchain: Reinventing Trust Relationships]. TEDxLyon, Lyon

Blockchain.info (n.d.). Average Number of Transactions per Block. https://Blockchain. info/charts/n-transactions-per-block. Accessed 17 Nov 2017

British Government Office for Science (2016) Distributed Ledger Technology: beyond block chain, https:/www.gov.uk/government/news/distributedledger-technology-beyond-block-chain. Accessed 25 July 2018

Drescher D (2017) Blockchain basics: a non-technical introduction in 25 steps. Apress, New York

Fair Food (2017) Living wage campaign. https://fairfood.nl/en/campaign/living-wage. Accessed 15 Nov 2017

Gorey C (2016). Irish start-up aid:tech using Blockchain to distribute aid in refugee camps. Silicon Republic, https://www.siliconrepublic.com/start-ups/aidtechrefugee-camps-blockchain. Accessed 25 July 2018
Kastelein R (2001) EU Parliament Approves Blockchain and Cryptocurrency Taskforce. Block chain News, https://www.the-blockchain.com/2016/05/30/eu-parliamentapproves-blockchain-and-cryptocurrency-task-force/. Accessed 25 July 2018. Weizsäcker von J (May 3, 2016) Report on virtual currencies. European Parliament doc. 2016/2007(INI), para. 22)

Keane J (2017). Why Sweden is taking a chance on Blockchain Land Registry. Coin Desk. https://www.coindesk.com/sweden-taking-chance-blockchainland-registry/. Accessed 25 July 2018

Kenny C (2017) How much aid is really lost to corruption? Center for Global Development. https://www.cgdev.org/blog/how-much-aid-really-lost-corruption. Accessed 25 July 2018

Kewell B, Adams R, Parry G (2017) Blockchain for good? Strateg Chang 26(5):429-437

Kshetri N (2017) Will Blockchain emerge as a tool to break the poverty chain in the Global South? Third World Q 38(8)

Marr B (2018) How Blockchain will transform the supply chain and logistics industry. Forbes. https:/www.forbes.com/sites/bernardmarr/2018/03/23/how-blockchainwill-transform-the-supply-chain-and-logistics-industry/. Accessed 25 July 2018

N/A (2015) The promise of the Blockchain: the trust machine. The Economist. https://www.economist.com/leaders/2015/10/31/the-trust-machine. Accessed 25 July 2018

Nakamoto S. (2008) Bitcoin: A Peer-to-Peer Electronic Cash System. https:// bitcoin.org/bitcoin.pdf. Accessed 25 July 2018

Poorterman A (2017). Start Network in new partnership with Disberse to test revolutionary technology. Start Network. https://startnetwork.org/news-andblogs/blockchain-experiment-humanitarian-aid. Accessed 25 July 2018. Purvis K. (January 17, 2017) Blockchain: what is it and what does it mean for development. The Guardian

Popper N (2015) Bitcoin Technology Piques Interest on Wall St. The New York Times. Jemima K. (October 28, 2015) Three banks join R3 Blockchain consortium taking total to 25 . Reuters

Preiss I (2017) Estonian e-residency offers transnational identity. Crypto Insider. https://cryptoinsider.21 mil.com/estonian-e-residency-offers-transnationalidentity/. Accessed 25 July 2018

Project Provenance Ltd. (2015) Blockchain: the solution for transparency in product supply chain. White Paper, Provenance.org, https://www.provenance.org/ whitepaper. Accessed 25 July 2018

Purvis K. (2017) Blockchain: what is it and what does it mean for development. The Guardian

Qadir J, Ali A, Rasool ur R, Zwitter A, Sathiaseelan A, Crowcroft J (2016) Crisis analytics: big data-driven crisis response. J Int Hum Action 1:12

Riani T (2018) Blockchain for social impact in aid and development. Humanitarian Advisory Group (blog), https://humanitarianadvisorygroup.org/blockchain-forsocial-impact-in-aid-and-development/

Sandle T (2018) Interview: Blockchain is overhauling humanitarian aid. Magazine, Digital Journal http://www.digitaljournal.com/business/interview-blockchainis-overhauling-humanitarian-aid/article/516119. Accessed 25 July 2018

Sundararajan S (2017) Moldova Eyes Blockchain IDs to help curb child trafficking. Coin Desk, https://www.coindesk.com/moldova-eyes-blockchain-ids-to-helpcurb-child-trafficking/. Accessed 25 July 2018. Dahan M (November 10, 2017) Humanitarian Blockchain Summit. YouTube, 45'05"-53'10", https://www.youtube. com/watch?v=Pwn3tEh_BU8. Accessed 25 July 2018

UN Women (2017). Oslo Hackathon explores new technology to empower women in humanitarian crisis. http://www.unwomen.org/en/news/stories/2017/6/ feature-oslo-hackathon-explores-new-technology-to-empower-women-inhumanitarian-crisis. Accessed 25 July 2018

Vermeend S (2017) Blockchain basics. Blockchain innovation conference, https:// blockchaininnovationconference.com/basics-need-know-understandblockchain-15-minutes-simone-vermeend/

Warburg B (2016) How the Blockchain will radically transform the economy. TED Summit

Zwitter A (2008) Humanitarian action on the battlefields of the global war on terror. J Hum Assist, http://sites.tufts.edu/jha/archives/223. Accessed 25 July 2018

Zwitter A and Herman J (2018), Blockchain for Sustainable Development Goals \#Blockchain4SDGs, Report 2018. Groningen University. https://www.rug.nl/cf/ events/events-items/blockchain4sdgs-workshop. (n.d.). Accessed 25 July 2018.

Zwitter A and Herman J (2018), Blockchain for Sustainable Development Goals \#Blockchain4SDGs, Report 2018. Groningen University. https://www.rug.nl/cf/ news/newsimages/180720-blockchain4sdgs-report-2018.pdf 